UDK 528.14

\title{
KOORDINAČIŲ KOREKTŪROS METODAS SUKURIANT GPS VIRTUALIĄSIAS REFERENCINES STOTIS
}

\author{
Jonas Skeivalas ${ }^{1}$, Silvija Gečyte் ${ }^{2}$ \\ Geodezijos ir kadastro katedra, Vilniaus Gedimino technikos universitetas, \\ Sauletekio al. 11, LT-10223 Vilnius-40, Lietuva, \\ el.paštas: ${ }^{1}$ Jonas.Skeivalas@ap.vtu.lt, ${ }^{2}$ Silvija.Gecyte@ap.vtu.lt
}

Iteikta 20051020 , priimta 20051214

\begin{abstract}
Santrauka. Straipsnyje analizuojamas GPS referencinių stočiu koordinačių korektūros modelio sudarymas. Modelis formuojamas virtualiosios referencinès stoties (VRS) pavidalu, kai stoties tikslios koordinatès nustatomos kaip GPS referencinių stočių tikslių koordinačių aritmetinis vidurkis. VRS stoties virtualiai išmatuotų koordinačių pataisos gaunamos kaip GPS referencinių stočių išmatuotų koordinačiu pataisų aritmetiniai arba svoriniai vidurkiai. GPS imtuvo vartotojas išmatuotas taškų koordinates koreguoja pataisomis, apskaičiuotomis pagal VRS transliuojamas koordinačiu pataisas.
\end{abstract}

Prasminiai žodžiai: GPS, virtualioji referencinė stotis (VRS), koordinačių pataisos.

\section{Ivadas}

Šis metodas pagrịstas tuo, kad GPS referencinès (bazinès, atraminès) stotys įrengiamos Žemès paviršiaus taškuose, kurių koordinatès tiksliai žinomos reikiamoje koordinačių sistemoje. Tam tikro skaičiaus GPS referencinių stočių matavimų duomenys virtualiujų referencinių stočių yra apibendrinami ir sisteminami. Taip patikimiau ir tiksliau nustatoma GPS signalu naudotojo padètis, priimant jau apdorotus ir modeliuotus signalus iš virtualiujuc stočių. GPS referencinès ir virtualiosios stotys telemetrinio ryšio kanalais transliuoja naudotojams koordinačių, pseudoatstumų, nešlio fazių pataisas tam tikrų modelių pavidalu. Šios pataisos naudotoju imtuvuose panaudojamos atitinkamiems matavimų rezultatams arba parametrų reikšmėms pataisyti [1-4].

Šiame straipsnyje analizuojama GPS virtualiosios referencinès stoties (VRS) transliuojamų koordinačiu pataisų modelių sudarymo eiga ir jų tikslumas.

\section{Virtualiųjų pataisų modelio sudarymas}

GPS referencinių stočių transliuojamos koordinačių, pseudoatstumų ir nešlio fazių pataisos keičiasi mažai, nedaug kintant atstumui (maždaug iki $10 \mathrm{~km}$ ) tarp GPS naudotojo imtuvo ir referencinès stoties. Tai lemia troposferos ir jonosferos būklè [5-7]. Todèl, referencines stotis išdèsčius didesniu atstumu, tenka sukurti GPS virtualiąsias stotis, kurios transliuoja iš referencinių stočių sudarytus pataisų modelius. Šie modeliai transliuojami nedelsiant (,realiuoju laiku“), bet gali būti naudojami ir „Postprocessing“ režimu, t. y. vartotojui patogiu laiku. Vartotojo padèties koordinačių pataisos priklauso nuo atstumo tarp vartotojo ir virtualiosios stoties bei krypties i i šią stoti [1-3].
Kadangi GPS referencinès stotys įrengiamos taškuose, kurių koordinatès tiksliai žinomos (keleto milimetrų ar centimetrų tikslumu), tai kiekviena GPS referencinè stotis pagal priimtus DŽP (dirbtinių Žemès palydovu) kodinius ir nešlio signalus nustatydama savo koordinates gali apskaičiuoti išmatuotų koordinačių pataisas:

$$
\delta T_{i}=\tilde{T}_{i}-T_{i}
$$

čia $\delta T_{i} \rightarrow\left(\delta X_{i}, \delta Y_{i}, \delta Z_{i}\right)^{T}-i$-osios referencinès stoties koordinačių pataisu vektorius; $T_{i} \rightarrow\left(X_{i}, Y_{i}, Z_{i}\right)^{T}-$ išmatuotų koordinačių vektorius; $\tilde{T}_{i} \rightarrow\left(\tilde{X}_{i}, \tilde{Y}_{i}, \tilde{Z}_{i}\right)^{T}-$ tikslių koordinačių vektorius.

Virtualiosios referencinès stoties (VRS) koordinates nustatysime kaip GPS referencinių stočiu tikslių koordinačių aritmetinį vidurkị:

$$
T_{V R S}=\frac{1}{r} \sum_{i=1}^{r} \tilde{T}_{i, r e f}
$$

čia $T_{V R S} \rightarrow\left(X_{V R S}, Y_{V R S}, Z_{V R S}\right)^{T}-$ VRS stoties tikslių koordinačių vektorius, $r$ - GPS referencinių stočių skaičius.

VRS stoties transliuojamas koordinačių pataisas nustatysime pagal GPS referencinių stočių transliuojamas pataisas pagal du variantus:

1) aritmetinių vidurkių pavidalu,

2) svorinių vidurkių pavidalu.

Pagal pirmaji variantą gauname

$$
\delta T_{V R S}=\frac{1}{r} \sum_{i=1}^{r} \delta T_{i}
$$


o pagal antraji variantą -

$$
\delta T_{V R S}^{\prime}=\frac{1}{\sum_{i}^{r} p_{i}} \sum_{i=1}^{n} p_{i} \delta T_{i}
$$

čia $p_{i}=p_{X_{i}}=p_{Y_{i}}=p_{Z_{i}}-i$-osios referencinès stoties koordinačių svoris. Referencinès stoties kiekvienos koordinatès svorius laikome vienodais ir skaičiuojame pagal formulę:

$$
p_{i}=\frac{c}{S_{i, V R S}}
$$

čia $c$ - laisvai parenkamas koeficientas. $S_{i, V R S}-$ atstumas tarp $i$-osios referencinès ir VRS stočių.

Mažiausiujų kvadratų metodu išlygintų dydžių $\delta T_{V R S}$ standartiniai nuokrypiai yra mažesni už išmatuotu dydžių standartinius nuokrypius vidutiniu koeficientu $\sqrt{k / n}[8,9]$. Aritmetiniai ir svoriniai vidurkiai atitinka mažiausiujų kvadratų metodu apskaičiuotas reikšmes, kai išmatuotų dydžių reikšmès atitinkamai yra vienodo ir nevienodo tikslumo. Taigi galime parašyti VRS koordinačių pataisų standartinių nuokrypių išraiškas:

$$
\sigma\left(\delta T_{V R S}\right)=\sqrt{k / n} \sigma\left(\delta T_{i}\right)_{v i d}
$$

čia $n=r, k=1-$ parametrų skaičius (VRS skaičius).

Pagal pirmaji variantą turime

$$
\sigma\left(\delta T_{V R S}\right)=\sqrt{1 / r} \sigma\left(\delta T_{i}\right)
$$

o pagal antraji variantą galime parašyti

$$
\sigma\left(\delta T_{V R S}^{\prime}\right)=1 / \sqrt{\sum_{i}^{r} p_{i}} \sigma_{0},
$$

čia $\sigma_{0}$ - matavimo rezultato, kurio svoris lygus vienetui, standartinis nuokrypis. Parametro $\sigma_{0}$ ivertis $m_{0}$ gali būti skaičiuojamas pagal formulę

$$
m_{0}^{2}=\frac{1}{r-1} \sum_{i=1}^{n} p_{i} V_{T_{i}}^{2}
$$

čia $V_{T_{i}}=\delta T_{V R S}^{\prime}-\delta T_{i}$ - pavienių GPS referencinių stočių koordinačių pataisų nuokrypių nuo VRS koordinačių pataisų vektorius.

\section{Praktinio taikymo modelis}

GPS referencinių stočių tinklo modeliui sudaryti buvo panaudota 12 Lietuvos GPS 2-osios klasès tinklo punktų ir parengti du tinklo modelio fragmentai (žr. pav.).

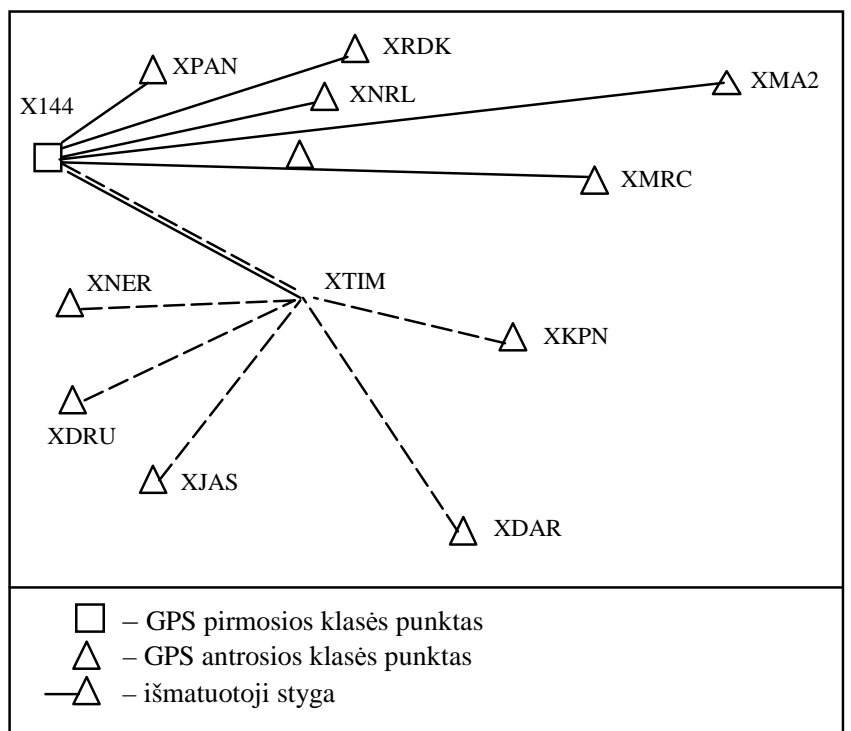

GPS referencinių stočių schema

Diagram of the GPS reference stations

Skaičiavimuose panaudotos punktų geodezinès koordinatès $B$ ir $L$, kurių tikslumas apibrèžiamas vidutinių kvadratinių nuokrypių reikšmėmis $m_{B} \approx m_{L} \approx 5 \cdot 10^{-4}{ }^{\prime \prime}-10^{-3}$. Geodezinių koordinačių nuokrypių išraiškų linijiniais ilgio vienetais atitikmuo maždaug toks: $0,001^{\prime \prime} \rightarrow 0,02 \mathrm{~m}$.

Viename modelio fragmente kaip virtualioji stotis panaudotas maždaug šešių GPS punktų tinklo viduryje esantis punktas TIM. Antrame modelio fragmente kaip virtualioji stotis panaudotas šešių GPS punktų tinklo pakraštyje esantis punktas 144. Didžiausias atstumas tarp GPS referencinių stočių buvo apie $31 \mathrm{~km}$, o mažiausias $6 \mathrm{~km}$. GPS referenciniu punktų apytikrès geodezinès koordinatès $B, L$ nustatytos panaudojus dvigubuosius nešlio fazių skirtumus per 10 minučių matavimų trukmès intervalą. Kaip tikslios GPS referencinių stočiu geodezinès koordinatès panaudotos GPS 2-osios klasès tinklo išlygintosios koordinatès; tinklui sudaryti matavimai buvo atliekami šešių valandų trukmès intervalais. Abiejuose referencinio tinklo modelio fragmentuose virtualiujų stočių geodezinių koordinačių pataisos buvo apskaičiuotos pagal du variantus: taikant aritmetinio vidurkio ir svorinio vidurkio principus. Skaičiavimų rezultatai pateikti 1 ir 2 lentelèse.

GPS referencinių stočių geodezinių koordinačių (išmatuotų, taikant 10 min. intervalą) pataisos skaičiuotos kaip nuokrypiai nuo jų tikslių reikšmių:

$$
\begin{aligned}
& \delta B_{i}=\tilde{B}_{i}-B_{i}, \\
& \delta L_{i}=\tilde{L}_{i}-L_{i},
\end{aligned}
$$

čia $\tilde{B}_{i}, \tilde{L}_{i}-$ tikslios koordinačių reikšmès; $B_{i}, L_{i}-$ išmatuotujų koordinačių reikšmès. 
1 lentelè. GPS referencinių punktų apytikrių geodezinių koordinačių $B, L$ pataisos $\delta B, \delta L$ (1 fragmentas) Table 1. Corrections of $\delta B, \delta L$ of GPS reference points approximate geodetic coordinates $B, L$ (1 fragment)

\begin{tabular}{|l|r|r|r|r|r|}
\hline \multirow{3}{*}{ GPS punktas } & \multicolumn{5}{|c|}{ Pataisos $\delta B^{\prime \prime}$} \\
& \multicolumn{1}{|c|}{$\delta$} \\
\cline { 2 - 6 } & \multicolumn{1}{|c|}{1} & \multicolumn{1}{|c|}{$\delta$} & \multicolumn{1}{|c|}{3} & \multicolumn{1}{c|}{4} \\
\hline \multirow{4}{*}{ DRU } & $-0,13696$ & 0,03032 & $-0,27886$ & 0,10525 & $-0,99157$ \\
& 0,45797 & $-0,09191$ & $-0,21218$ & $-0,13850$ & 1,45856 \\
& $-0,13189$ & 0,02846 & $-0,32246$ & 0,11070 & $-1,01539$ \\
KPN & 0,47237 & $-0,10367$ & $-0,30020$ & $-0,12780$ & 1,42860 \\
& $-0,13626$ & 0,02300 & $-0,28361$ & 0,10439 & $-0,99280$ \\
NER & 0,47188 & $-0,10768$ & $-0,22588$ & $-0,14175$ & 1,48068 \\
& $-0,13325$ & 0,02931 & $-0,27968$ & 0,10520 & $-0,98973$ \\
DAR & 0,47165 & $-0,08639$ & $-0,20321$ & $-0,12901$ & 1,48061 \\
& $-0,13786$ & 0,02806 & $-0,27076$ & 0,10460 & $-1,00706$ \\
144 & 0,46389 & $-0,09979$ & $-0,21427$ & $-0,14051$ & 1,45362 \\
& $-0,13107$ & 0,02888 & $-0,28086$ & 0,10503 & $-0,98711$ \\
& 0,46131 & $-0,09656$ & $-0,21308$ & $-0,13941$ & 1,47217 \\
\hline
\end{tabular}

Aritmetinio vidurkio principu pataisytų koordinačiu nuokrypiai $\delta T_{V R S}$ nuo tikslių

\begin{tabular}{l|l|l|l|l|l|} 
& & \multicolumn{3}{|c|}{ reikšmių } \\
virtualioji & 0,00023 & 0,00142 & 0,00657 & $-0,00076$ & 0,00490 \\
GPS stotis & 0,00082 & 0,00066 & 0,01081 & $-0,00275$ & 0,01175 \\
TIM & & & &
\end{tabular}

Svorinio vidurkio principu pataisytų koordinačių nuokrypiai $\delta T_{V R S}^{\prime}$

\begin{tabular}{|r|r|r|r|r|} 
& \multicolumn{5}{|c|}{ nuo tikslių reikšmiu } \\
$-0,00048$ & 0,00182 & 0,00502 & 0,00640 & $-0,00065$ \\
0,00014 & 0,00142 & 0,01061 & 0,01091 & $-0,00249$ \\
\hline
\end{tabular}

2 lentelè. GPS referencinių punktų apytikrių geodezinių koordinačių $B, L$ pataisos $\delta B, \delta L$ (2 fragmentas) Table 2. Corrections of $\delta B, \delta L$ of GPS reference points approximate geodetic coordinates $B, L$ (2 fragment)

\begin{tabular}{|c|c|c|c|c|c|c|}
\hline \multirow[t]{2}{*}{ GPS punktas } & \multicolumn{6}{|c|}{$\begin{array}{r}\text { Pataisos } \delta B^{\prime \prime} \\
\delta L^{\prime \prime}\end{array}$} \\
\hline & 1 & 2 & 3 & 4 & 5 & \\
\hline MRC & $\begin{array}{l}-1,66798 \\
-0,73817\end{array}$ & $\begin{array}{c}-0,49109 \\
0,37581\end{array}$ & $\begin{array}{l}0,06393 \\
0,20666\end{array}$ & $\begin{array}{l}-0,43607 \\
-0,12471\end{array}$ & $\begin{array}{l}2,46822 \\
1,01970\end{array}$ & $\begin{array}{c}-0,18202 \\
0,29276\end{array}$ \\
\hline RDK & $\begin{array}{l}-1,66880 \\
-0,74520\end{array}$ & $\begin{array}{c}-0,48591 \\
0,38875\end{array}$ & $\begin{array}{l}0,06644 \\
0,19391\end{array}$ & $\begin{array}{l}-0,43779 \\
-0,11598\end{array}$ & $\begin{array}{l}2,46427 \\
1,01833\end{array}$ & $\begin{array}{c}-0,18490 \\
0,29670\end{array}$ \\
\hline TIM & $\begin{array}{l}-1,66758 \\
-0,73832\end{array}$ & $\begin{array}{c}-0,48617 \\
0,38783\end{array}$ & $\begin{array}{l}0,06469 \\
0,19946\end{array}$ & $\begin{array}{l}-0,43317 \\
-0,11557\end{array}$ & $\begin{array}{l}2,46986 \\
1,01817\end{array}$ & $\begin{array}{r}-0,17937 \\
0,28843\end{array}$ \\
\hline MA2 & $\begin{array}{l}-1,66277 \\
-0,73907\end{array}$ & $\begin{array}{c}-0,48435 \\
0,39119\end{array}$ & $\begin{array}{l}0,06777 \\
0,20387\end{array}$ & $\begin{array}{l}-0,43743 \\
-0,12314\end{array}$ & $\begin{array}{l}2,46110 \\
1,01905\end{array}$ & $\begin{array}{c}-0,18726 \\
0,29643\end{array}$ \\
\hline NRL & $\begin{array}{l}-1,66136 \\
-0,72856\end{array}$ & $\begin{array}{c}-0,48159 \\
0,40620\end{array}$ & $\begin{array}{l}0,05983 \\
0,18417\end{array}$ & $\begin{array}{l}-0,45961 \\
-0,14549\end{array}$ & $\begin{array}{l}2,47295 \\
1,03475\end{array}$ & $\begin{array}{c}-0,18109 \\
0,30875\end{array}$ \\
\hline PAN & $\begin{array}{l}-1,66818 \\
-0,74763\end{array}$ & & $\begin{array}{l}0,06676 \\
0,19716\end{array}$ & $\begin{array}{l}-0,43684 \\
-0,12283\end{array}$ & $\begin{array}{l}2,46763 \\
1,01373\end{array}$ & $\begin{array}{c}-0,18661 \\
0,28928\end{array}$ \\
\hline \multicolumn{7}{|c|}{ Aritmetinio vidurkio principu pataisytų koordinačių nuokrypiai $\delta T_{V R S}$ nuo tikslių reikšmių } \\
\hline $\begin{array}{l}\text { virtualioji PS } \\
\text { stotis } 144\end{array}$ & $\begin{array}{c}-0,00021 \\
0,00052\end{array}$ & $\begin{array}{c}0,00087 \\
-0,00129\end{array}$ & $\begin{array}{c}0,00159 \\
-0,00260\end{array}$ & $\begin{array}{l}0,00410 \\
0,00996\end{array}$ & $\begin{array}{c}0,00192 \\
-0,00254\end{array}$ & $\begin{array}{c}-0,00051 \\
0,01492\end{array}$ \\
\hline \multicolumn{7}{|c|}{ Svorinio vidurkio principu pataisytų koordinačių nuokrypiai $\delta T_{V R S}^{\prime}$ nuo tikslių reikšmių } \\
\hline & $\begin{array}{l}0,00035 \\
0,00237\end{array}$ & $\begin{array}{c}0,00050 \\
-0,00217\end{array}$ & $\begin{array}{c}0,00137 \\
-0,00137\end{array}$ & $\begin{array}{l}0,00392 \\
0,00983\end{array}$ & $\begin{array}{c}0,00131 \\
-0,00123\end{array}$ & $\begin{array}{c}-0,00006 \\
0,01624\end{array}$ \\
\hline
\end{tabular}


Taikant aritmetinio ar svorinio vidurkių principus apskaičiuotų abiejų virtualiujų stočių geodeziniu koordinačių nuokrypiai nuo tikslių koordinačių reikšmių yra maždaug tos pačios eilès (1 ir 2 lentelèse). GPS referencinių stočių pataisytų apytikrių geodezinių koordinačių $B, L$ reikšmès, kurios skaičiuojamos pagal formules

$$
\begin{aligned}
& \tilde{B}_{i}=B_{i}+\delta B_{i}, \\
& \tilde{L}_{i}=L_{i}+\delta L_{i},
\end{aligned}
$$

nustatytos standartinių nuokrypių iverčiais $m_{\tilde{B}}=0,0024^{\prime \prime}$ ir $m_{\tilde{B}}=0,0063^{\prime \prime}$. Virtualiujų GPS stočių TIM ir 144 geodezinių koordinačių $\tilde{B}_{V R S}, \tilde{L}_{V R S}$, nustatytu, taikant aritmetinio ir svorinio vidurkiuc principus, tikslumas yra maždaug tos pačios eilès, t. y.

$$
m_{V R S, \tilde{B}}=0,0010^{\prime \prime} ; m_{V R S, \tilde{L}}=0,0026^{\prime \prime}
$$

ir

$$
m_{V R S, \tilde{B}}^{\prime}=0,0011^{\prime \prime} ; m_{V R S, \tilde{L}}^{\prime}=0,0025^{\prime \prime} .
$$

\section{Išvados}

1. Taikant virtualiąsias GPS referencines stotis (VRS) padideja vartotojo imtuvais realiuoju laiku ar „postprocessing“ režimu, t. y. GPS vartotojui patogiu laiku, nustatytų koordinačių tikslumas.

2. Pasiūlytas VRS stočiu sudarymo modelis, koordinačių pataisoms nustatyti taikant aritmetinio vidurkio ir svorinio vidurkio principus.

3. Akivaizdu, kad GPS vartotojo imtuvais nustatytu koordinačių tikslumas, pasirinkus virtualiujų stočių modeli, yra maždaug tos pačios eilès, taikant aritmetinio vidurkio ar svorinio vidurkio principus.

\section{Literatūra}

1. Lambert Wanninger. Virtuelle GPS-Referenzstationen für grossräumige kinematische Anwendungen. Zeitschrift für Vermessungswesen, No 3. Stuttgart: Verlag K. Witwer, 2003, S. 196-202.

2. Hankemeier, P. Der Satellitenpositionierungsdienst SAPOS in Deutschland. Multifunktionale GNSSReferenzstationsysteme für Europa. Workshop von 4. 5. März 2002 in der Europäischen Akademie für städtische Umwelt. Berlin, 2002, S. 16-23.
3. Teunissen, P. J. G. The parameter distributions of the integer GPS model. Journal of Geodesy, No 1 (76). 2002, p. 41-48.

4. Skeivalas, J. Accuracy determination of the coordinates augmentations of GPS vectors by measuring double phase shifts of the carrier. Geodesy and Cartography (Geodezija ir kartografija), Vol XXIX, No 4. Vilnius: Technika, 2003, p. 115-118 (in Lithuanian).

5. Bauer, M. Vermessung und Ortung mit Satelliten. Heidelberg: Wichmann, 1994. 274 S.

6. Hofmann-Wellenhof, B.; Lichtenegger, H. and Collins, J. Global Positioning System. In: Theory and Practice. Wien, New York: Springer-Verlag, 1992. 326 p.

7. Leick, A. GPS Satellite Surveying. New York, Chichester, Brisbane, Toronto, Singapore: John Wiley and Sons. 1995, $352 \mathrm{p}$.

8. Koch, K. R. Einführung in die Bayes-Statistik. SpringerVerlag Berlin Heidelberg, 2000. 225 S.

9. Markuze, J. I. Algorithms for geodetic networks adjustment using computers (Алгоритмы для уравнивания геодезических сетей на ЭВМ). Moscow: Nedra, 1989. 248 p. (in Russian).

\section{Jonas SKEIVALAS. Prof, Doctor Habil.}

Vilnius Gediminas Technical University. Dept of Geodesy and Cadastre, Saulètekio al. 11, LT-10223 Vilnius-40, Lithuania $(\mathrm{Ph}+3705$ 2744703, Fax +370 5 2744705), e-mail: jonas.skeivalas@ap.vtu.lt.

Author of two monographs and more than 130 scientific papers. Participated in many intern conferences and research visits to the Finish Geodetic Institute.

Research interests: processing of measurements with respect to tolerances, adjustment of geodetic networks.

\footnotetext{
Silvija GEČYTE். Master of Science.

Vilnius Gediminas Technical University. Dept of Geodesy and Cadastre, Saulètekio al. 11, LT-10223 Vilnius-40, Lithuania $(\mathrm{Ph}+3705$ 2744703, Fax +370 5 2744705), e-mail: silvija.gecyte@ap.vtu.lt.

Research interests: digital maps, GPS satellite surveyings.
} 